\title{
Immunoreactive insulin in diabetes mellitus patient sera detected by ultrasensitive ELISA with thio-NAD cycling
}

Etsuro Ito ${ }^{1}$, Mugiho Kaneda ${ }^{1}$, Hiromi Kodama ${ }^{1}$, Mika Morikawa ${ }^{1,2}$, Momoko Tai ${ }^{1}$, Kana Aoki ${ }^{1}$, Satoshi Watabe ${ }^{3}$, Kazunari Nakaishi², Seiichi Hashida ${ }^{4}$, Satoshi Tada ${ }^{5,6}$, Noriyuki Kuroda ${ }^{5}$, Hitomi Imachi ${ }^{5}$, Koji Murao ${ }^{5}$, Masakane Yamashita7, Teruki Yoshimura ${ }^{8}$, and Toshiaki Miura ${ }^{9}$ ${ }^{1}$ Kagawa School of Pharmaceutical Sciences, Tokushima Bunri University, Sanuki, Japan, ${ }^{2} R \& D$ Headquarters, TAUNS Laboratories, Inc., Izunokuni, Japan, ${ }^{3} R \& D$ Department, BL Co. Ltd., Izunokuni, Japan, ${ }^{4}$ Institute for Health Sciences, Tokushima Bunri University, Tokushima, Japan, ${ }^{5}$ Faculty of Medicine, Kagawa University, Miki, Japan, ${ }^{6}$ Department of Medical Technology, Kagawa Prefectural University of Health Sciences, Takamatsu, Japan, 'Faculty of Science, Hokkaido University, Sapporo, Japan, ${ }^{8}$ Faculty of Pharmaceutical Sciences, Health Sciences University of Hokkaido, Ishikari-Tobetsu, Japan, and ${ }^{9}$ Graduate School of Pharmaceutical Sciences, Hokkaido University, Sapporo, Japan

BioTechniques 59:359-367 (December 2015) doi 10.2144/000114355

Keywords: diabetes mellitus; ELISA; enzyme cycling; insulin; thio-NAD cycling

Supplementary material for this article is available at www.BioTechniques.com/article/114355.

To minimize patient suffering, the smallest possible volume of blood should be collected for diagnosis and disease monitoring. When estimating insulin secretion capacity and resistance to insulin in diabetes mellitus (DM), increasing insulin assay immunosensitivity would reduce the blood sample volume required for testing. Here we present an ultrasensitive ELISA coupled with thio-NAD cycling to measure immunoreactive insulin in blood serum. Only $5 \mu \mathrm{L}$ of serum was required for testing, with a limit of detection (LOD) for the assay of $10^{-16}$ moles/assay. Additional recovery tests confirmed this method can detect insulin in sera. Comparisons between a commercially available immunoreactive insulin kit and our ultrasensitive ELISA using the same commercially available reference demonstrated good data correlation, providing further evidence of assay accuracy. Together, these results demonstrate our ultrasensitive ELISA could be a powerful tool in the diagnosis and treatment of not only DM but also many other diseases in the future.

Insulin is a peptide hormone secreted from $\beta$ cells in pancreatic islets that serves as a signal of the fed state (1). It is central to regulating carbohydrate and fat metabolism in the body (2). Normally, insulin is secreted in a constant proportion to remove excess glucose from the blood (3); however, this is not the case in patients with the metabolic disorder diabetes mellitus (DM) or metabolic syndrome. When control of insulin levels fails, DM can result (www. diabetes.niddk.nih.gov/dm/pubs/ type1and2/index.aspx). DM occurs in two major forms: insulin-dependent
(Type 1) and non-insulin-dependent (Type 2). Patients with Type 2 DM are often insulin-resistant and therefore may suffer from a relative insulin deficiency. In both Type 1 and Type 2 DM, the blood insulin concentration (i.e., immunoreactive insulin) should be carefully measured to estimate insulin secretional capacity and insulin resistance (4-6).

Because DM patients, as well as those with various other conditions, must undergo frequent blood sampling, efforts should be made to reduce the volume of blood per sample required for testing (7-10). One way to accomplish this is to increase the measurement sensitivity for particular target proteins. In particular, reduction of blood sample volume is very important in the case of infants with Type 1 DM. Blood collection from infants is very difficult, and the amount collected per sample is very small (11). Thus, an ultrasensitive assay for insulin has been strongly desired for progression-monitoring of DM in infants.

The sandwich enzyme-linked immunosorbent assay (ELISA) is a suitable method for precisely quantifying trace amounts of proteins (12). The ELISA for insulin was established in the 1980s and 1990s. The limits of detection (LODs) at

\section{METHOD SUMMARY}

The combination of a sandwich ELISA with a thio-NAD cycling method enables the ultrasensitive detection of immunoreactive insulin in patient sera by measuring the quantity of thio-NADH generated. This approach allows for the detection of trace amounts of immunoreactive insulin just by the application of thio-NAD cycling reagents to the standard ELISA system. 
Table 1. Protocol for additional recovery test using recombinant human insulin and human serum.

\begin{tabular}{|c|c|c|c|c|}
\hline Serum & \multicolumn{2}{|c|}{ Blank (only including insulin in serum) } & \multicolumn{2}{|c|}{$\begin{array}{l}\text { Recombinant human insulin }(2.8 \mu \mathrm{lU} / \mathrm{mL} \text { ) } \\
\text { (Ray Biotech) (i.e., endogenous insulin in } \\
\text { serum }+2.8 \mu \mathrm{lU} / \mathrm{mL} \text { insulin) }\end{array}$} \\
\hline \multirow[t]{3}{*}{ DM-patient serum 0} & no dilution & Solution 1 & no dilution & Solution 3 \\
\hline & $\begin{array}{l}1: 10 \\
(2.5 \mu \mathrm{L} / 25 \mu \mathrm{L})\end{array}$ & \multirow[t]{10}{*}{ Solution 2} & $\begin{array}{l}1: 10 \\
(2.5 \mu \mathrm{L} / 25 \mu \mathrm{L})\end{array}$ & \multirow[t]{10}{*}{ Solution 4} \\
\hline & $\begin{array}{l}1: 20 \\
(1.25 \mu \mathrm{L} / 25 \mu \mathrm{L})\end{array}$ & & $\begin{array}{l}1: 20 \\
(1.25 \mu \mathrm{L} / 25 \mu \mathrm{L})\end{array}$ & \\
\hline \multirow[t]{3}{*}{ DM-patient serum 120} & $\begin{array}{l}1: 10 \\
(2.5 \mu \mathrm{L} / 25 \mu \mathrm{L})\end{array}$ & & $\begin{array}{l}1: 10 \\
(2.5 \mu \mathrm{L} / 25 \mu \mathrm{L})\end{array}$ & \\
\hline & $\begin{array}{l}1: 50 \\
(0.5 \mu \mathrm{L} / 25 \mu \mathrm{L})\end{array}$ & & $\begin{array}{l}1: 50 \\
(0.5 \mu \mathrm{L} / 25 \mu \mathrm{L})\end{array}$ & \\
\hline & $\begin{array}{l}1: 100 \\
(0.25 \mu \mathrm{L} / 25 \mu \mathrm{L})\end{array}$ & & $\begin{array}{l}1: 100 \\
(0.25 \mu \mathrm{L} / 25 \mu \mathrm{L})\end{array}$ & \\
\hline \multirow[t]{2}{*}{ Control serum low } & $\begin{array}{l}1: 10 \\
(2.5 \mu \mathrm{L} / 25 \mu \mathrm{L})\end{array}$ & & $\begin{array}{l}1: 10 \\
(2.5 \mu \mathrm{L} / 25 \mu \mathrm{L})\end{array}$ & \\
\hline & $\begin{array}{l}1: 20 \\
(1.25 \mu \mathrm{L} / 25 \mu \mathrm{L})\end{array}$ & & $\begin{array}{l}1: 20 \\
(1.25 \mu \mathrm{L} / 25 \mu \mathrm{L})\end{array}$ & \\
\hline \multirow[t]{3}{*}{ Control serum high } & $\begin{array}{l}1: 10 \\
(2.5 \mu \mathrm{L} / 25 \mu \mathrm{L})\end{array}$ & & $\begin{array}{l}1: 10 \\
(2.5 \mu \mathrm{L} / 25 \mu \mathrm{L})\end{array}$ & \\
\hline & $\begin{array}{l}1: 50 \\
(0.5 \mu \mathrm{L} / 25 \mu \mathrm{L})\end{array}$ & & $\begin{array}{l}1: 50 \\
(0.5 \mu \mathrm{L} / 25 \mu \mathrm{L})\end{array}$ & \\
\hline & $\begin{array}{l}1: 100 \\
(0.25 \mu \mathrm{L} / 25 \mu \mathrm{L})\end{array}$ & & $\begin{array}{l}1: 100 \\
(0.25 \mu \mathrm{L} / 25 \mu \mathrm{L})\end{array}$ & \\
\hline
\end{tabular}

that time were on the order of $\mu \mathrm{lU} / \mathrm{mL}$, which corresponded to tens of femtomoles per milliliter. The molecular weight of human insulin is 5807, and for this conversion, 1 IU was estimated as $\sim 43 \mu \mathrm{g}$ (www.nibsc. org/documents/ifu/66-304.pdf). For example, Bürgi et al. demonstrated that their sandwich ELISA detected insulin at $3.7 \mathrm{mlU} / \mathrm{L}$, which corresponded to $\sim 2.8$ $\times 10^{-14} \mathrm{moles} / \mathrm{mL}$ (13). Storch et al. could detect insulin at $2 \mu \mathrm{lU} / \mathrm{mL}$, which was $\sim 1.5 \times 10^{-14}$ moles $/ \mathrm{mL}$ (14). Mecklenburg et al. could detect it at $0.025 \mu \mathrm{g} / \mathrm{mL}$, corresponding to $4.3 \times 10^{-12} \mathrm{moles} / \mathrm{mL}$ (15). The measurements obtained by Andersen et al. were very sensitive: 5 picomoles/L (5 $\times 10^{-15} \mathrm{moles} / \mathrm{mL}$ ) (16). Recently, assays for insulin have moved to lab-on-a-chip methods. Using these methods, Park et al. showed that the detection level of insulin was $0.4 \mathrm{ng} / \mathrm{mL}$, or $6.9 \times 10^{-14} \mathrm{moles} / \mathrm{mL}$ (17), and Oyama et al. detected $17 \mathrm{ng} / \mathrm{mL}$, or $2.9 \times 10^{-12}$ moles $/ \mathrm{mL}$ (18). Thus, these newer methods have never exceeded the limitation of the ELISA methods, and the overall LOD for insulin reported so far is on the order of $10^{-14}$ moles $/ \mathrm{mL}$.

More recently, Watabe et al. proposed a novel ultrasensitive ELISA in which a sandwich ELISA is combined with enzyme cycling (19). Enzyme cycling assays measure trace amounts of substrate using amplification techniques $(20,21)$. Thus, a detectable signal is amplified in the a quadratic function-like response, resulting in an LOD for human insulin of $10^{-19}$ moles/ assay using recombinant human insulin
(19). Watabe et al. showed that their ultrasensitive determination was at least 4 orders of magnitude more sensitive than other highly sensitive methods reported in the literature (19).

Here we describe an ultrasensitive ELISA for immunoreactive insulin that we tested using human sera obtained from DM patients, using World Health Organization (WHO) international standard insulin or its equivalent products, widely used at clinical sites, as references. Our results confirm that the sensitivity of this technique was sufficiently high and reliable enough to determine immunoreactive insulin in DM-patient sera.

\section{Materials and methods Chemicals}

Insulin as an antigen for ELISA was purchased from the following companies: The WHO international standard distributed by the National Institute for Biological Standards and Control (NIBSC), NIBSC code (66/304), was purchased from the Health Care Technology Foundation (Tokyo, Japan). The reference insulin included in the TOSOH II (IRI) kit (Tosoh, Tokyo, Japan) was also used in this study. Three kinds of recombinant human insulin were purchased from Kamiya Biomedical (Seattle, WA), Ray Biotech (Norcross, GA) and BioVision (Milpitas, CA). Intact proinsulin distributed by the NIBSC, NIBSC code (09/296), was purchased from the Health Care Technology Foundation. C-peptide was purchased from Anaspec

\section{KAPA Stranded RNA-Seq Kits with RiboErase}

\section{Comprehensive high-quality transcriptome profiling}

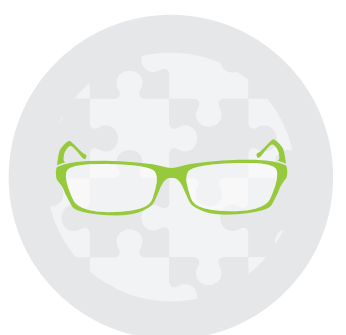

Comprehensive view

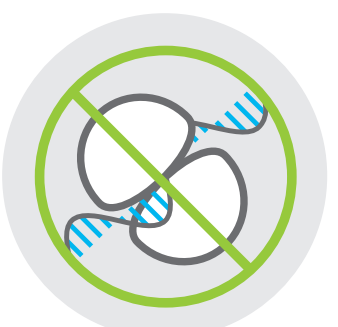

Up to $99.98 \%$ removal

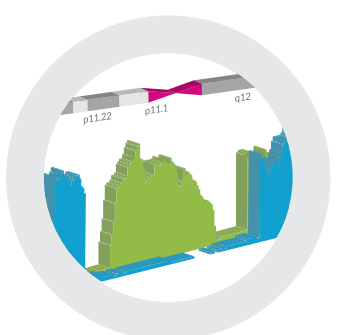

Uncover difficult transcripts

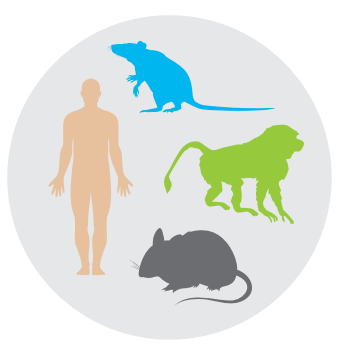

Multiple sample types

\section{Visit}

kapabiosystems.com/riboerase

to request a trial kit 
(Fremont, CA). The primary and secondary antibodies for anti-human insulin were: monoclonal mouse 7F8 antibody (Cat. \# 211; HyTest, Turku, Finland) and monoclonal mouse D4B8 antibody (Cat. \# 211; HyTest), respectively. The secondary antibody, which was linked to alkaline phosphatase (AP) (EC. 3.1.3.1), digested to $F\left(a b^{\prime}\right)_{2}$ by pepsin, and reduced to Fab' by 2-mercaptoethylamine. A maleimide terminal was then introduced by reacting AP with N-(6-maleimidocaproyloxy (sulfo-EMCS) purchased from Dojindo, Kumamoto, Japan. Finally, an SH group on Fab' and a maleimide terminal on AP were joined. Thionicotinamideadenine dinucleotide (thio-NAD) and $\mathrm{NADH}$ were purchased from Roche (Mannheim, Germany). 3 $\alpha$-hydroxysteroid dehydrogenase ( $3 \alpha-\mathrm{HSD}$; derived from Comamonas testosteroni and recombined by $E$. coli) was purchased from Kikkoman Biochemifa (Tokyo, Japan) and purified by BL Co., Ltd. (Izunokuni, Japan). $5 \beta$-androsterone was purchased from Steraloids (Newport, RI). 17 $\beta$-Methoxy$5 \beta$-androstan-3 $\alpha$-ol 3-phosphate was synthesized as described previously (19). Absorption was measured at $405 \mathrm{~nm}$ with a Corona Electric MTP-500 microplate reader (Hitachinaka, Japan) thermostated at $37^{\circ} \mathrm{C}$.

\section{Human sera}

Blood was taken from DM patients at Kagawa University Hospital, and the sera were separated by centrifugation. Our method requires only $5 \mu \mathrm{L}$ serum per sample( i.e., a blood sample of $\sim 10$ $\mu L)$. In contrast, a commercially available method, for example the TOSOH II (IRI) kit, which is used at Kagawa University Hospital, requires at least $200 \mu \mathrm{L}$, including the dead volume; thus, the blood sample must be at least $500 \mu \mathrm{L}$. The serum samples were cryopreserved at $-80^{\circ} \mathrm{C}$. We avoided repeated freeze/ thaw cycles beyond the minimum necessary (22). The experiments using human blood were performed with the permission of the Ethics Committees of Tokushima Bunri University and Kagawa University. Control sera were purchased from Eiken (Tochigi, Japan).

\section{Ultrasensitive ELISA coupled}

with thio-NAD cycling

The primary antibody solution, which was adjusted to $20 \mu \mathrm{g} / \mathrm{mL}$ in a $50 \mathrm{mM}$ $\mathrm{Na}_{2} \mathrm{CO}_{3}$ solution ( $\mathrm{pH}$ 9.6), was added to 96-well microplates in aliquots of $50 \mu \mathrm{L}$ per well and incubated for $1 \mathrm{~h}$ at room temperature. The microplates were washed with Tris-buffered saline (TBS) including 0.05\% Tween 20 and incubated with $20 \%$ Blocking One-P (Nacalai Tesque, Kyoto, Japan) for 45 min at room temperature. The microplates were again washed 3 times with TBS including $0.05 \%$ Tween 20. Then, an antigen or a serum was added at $50 \mu \mathrm{L}$ per well. The sera were diluted $10 \times$ with TBS including 5\% Blocking One-P. Note that this dilution was taken into account when approximating the sensitivity. The microplates were shaken for $60 \mathrm{~min}$ at room temperature and then washed with TBS including $0.05 \%$ Tween 20 . The solution containing the secondary antibody (linked to AP) was adjusted to $5 \times 10^{-15} \mathrm{moles} / \mathrm{mL}$ in TBS including 0.05\% Tween 20 and 5\% Blocking One-P before being added to the plate at 50 $\mu \mathrm{L}$ per well. The microplates were kept overnight at $4^{\circ} \mathrm{C}$ and washed 9 times with TBS including 0.05\% Tween 20. To amplify the ELISA signal, $50 \mu \mathrm{L}$ thio-NAD cycling solution was added to each well. This solution contains $1.0 \mathrm{mM}$ NADH, 1.5 $\mathrm{mM}$ thio-NAD, $0.25 \mathrm{mM} 17 \beta$-methoxy- $5 \beta$ androstan-3 $\alpha$-ol 3-phosphate, and $5 \mathrm{U} /$ $\mathrm{mL} 3 \alpha-\mathrm{HSD}$ in $100 \mathrm{mM}$ Tris- $\mathrm{HCl}$ (pH 9.0). Absorbance at $405 \mathrm{~nm}$ was measured with a microplate reader every 5 min for

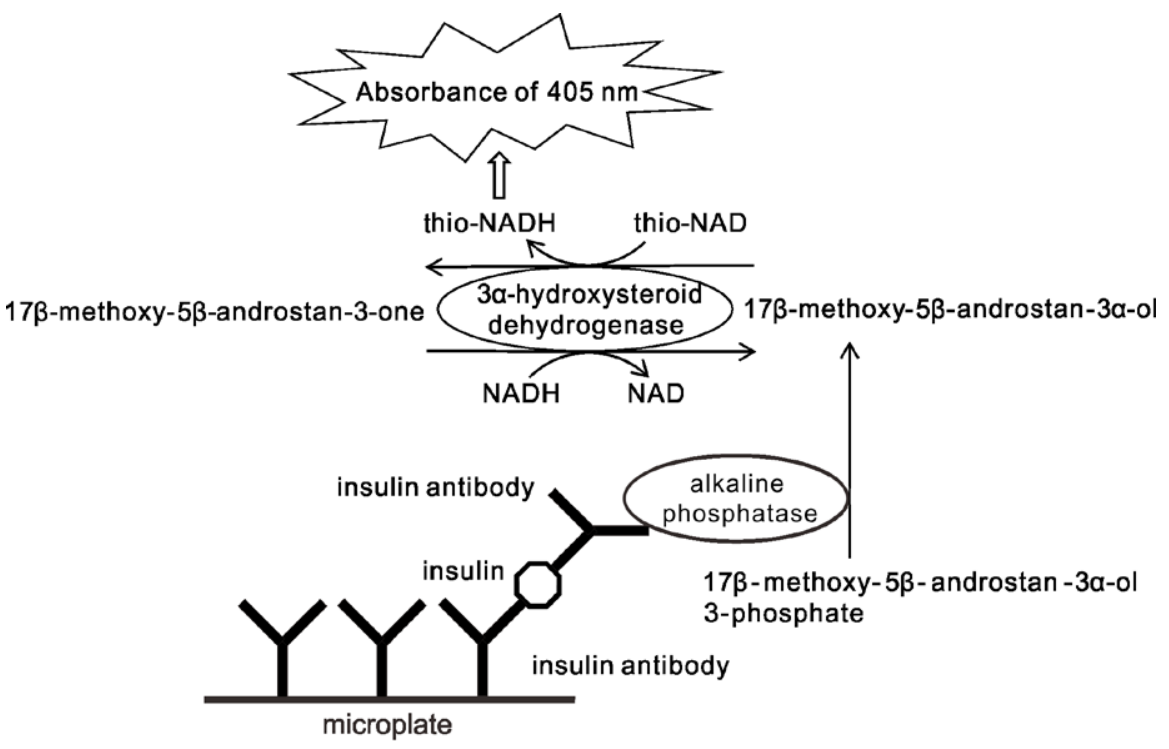

Figure 1. Ultrasensitive detection of insulin in serum by ELISA coupled with thio-NAD cycling using alkaline phosphatase, androsterone derivatives, $3 \alpha$-hydroxysteroid dehydrogenase, and its coenzymes. During the cycling reaction, thio- $\mathrm{NADH}$ accumulates in a quadratic function-like fashion with time. Accumulated thio- $\mathrm{NADH}$ can be measured directly by absorbance at $400 \mathrm{~nm}$ (i.e., 405 $\mathrm{nm}$ with a commercially available microplate reader) without any interference from other cofactors.
60 min at $37^{\circ} \mathrm{C}$. A detailed protocol can be found in the Supplementary Material.

\section{Additional recovery test}

The experimental procedures for this test were the same as for the ultrasensitive ELISA experiments without the antigen solutions (Table 1) containing:

\section{Solution 1: $50 \mu \mathrm{L}$ TBS including 5\%} Blocking-One P.

Solution 2: $25 \mu \mathrm{L}$ 5\% Blocking-One P, $50 \mathrm{mM} \mathrm{NaCl}, 10 \mathrm{mM}$ PIPES-HCl, and $25 \mu \mathrm{L}$ human control serum, which was diluted 10-1000× with TBS including 5\% Blocking-One P (see Table 1).

Solution 3: $25 \mu \mathrm{L}$ recombinant human insulin (Ray Biotech) at a concentration of $0.14 \mu \mathrm{IU} / 25 \mu \mathrm{L}$ and $25 \mu \mathrm{L}$ TBS including 5\% Blocking-One P.

Solution 4: $25 \mu \mathrm{L}$ recombinant human insulin (Ray Biotech) at a concentration of $0.14 \mu \mathrm{IU} / 25 \mu \mathrm{L}$ and $25 \mu \mathrm{L}$ human serum, which was diluted 10-1000x with TBS including 5\% Blocking-One $P$ (see Table 1).

The additional recovery ratio was calculated as: [\{the absorbance of Solution 4 - that of Solution 1 \} - \{the absorbance of Solution 2 - that of Solution 1\}] / [the absorbance of Solution 3 - that of Solution 1]. solution. We prepared four types of 

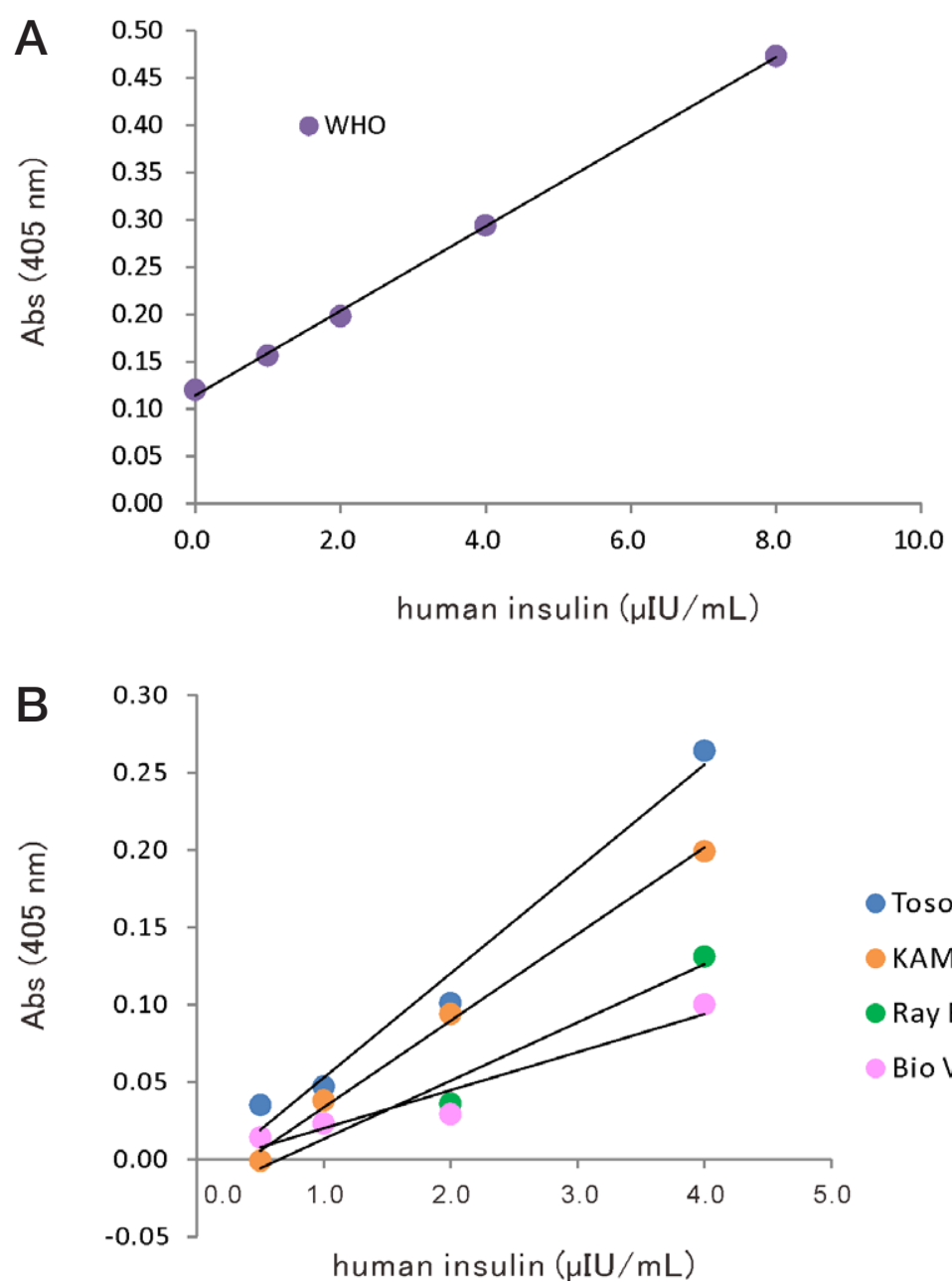

Figure 2. Linear calibration curves for ultrasensitive ELISA coupled with thio-NAD cycling using commercially available insulin references. (A) Ultrasensitive ELISA calibration curve for the WHO international standard insulin reference. The absorbance of thio-NADH was measured at $405 \mathrm{~nm}$ after a cycling reaction time of $60 \mathrm{~min}$. The linear regression equation is for the curve is $y=0.045 x$ $+0.11, R^{2}=1.00$. The blank values (i.e., the absorbances of the $0 \mu \mathrm{lU} / \mathrm{mL}$ insulin samples) were not subtracted from the absorbances of the other concentrations of insulin because this linear curve was needed to calculate the limit of detection and the limit of determination. (B) Ultrasensitive ELISA calibration curves for other insulin references. The blank values (i.e., the absorbances of the $0 \mu \mathrm{IU} / \mathrm{mL}$ insulin samples) were subtracted from the absorbances of the other concentrations of insulin. That is, this figure directly expresses the values corresponding to the concentrations of insulin. The equation for the linear calibration curve using the reference in the TOSOH II (IRI) kit was $y=0.067 x-0.015$, $R^{2}=0.99$; that for the recombinant human insulin from Kamiya Biomedical was $y=0.056 x-0.023$, $R^{2}=1.00$; that for the recombinant human insulin from Ray Biotech was $y=0.038 x-0.025, R^{2}=$ 0.95; and that for the recombinant human insulin from BioVision was $y=0.025 x-0.005, R^{2}=0.93$.

Limit of detection, limit of determination, and coefficient of variation

The experimental data were obtained by subtracting the mean value of the blank signals from each of the corresponding measurements. The LOD was estimated from the mean of the blank, the standard deviation of the blank, and a confidence factor of 3. The limit of determination was estimated by the same method as used for the LOD, but with a confidence factor of 10 . The coefficient of variation calculated from 3 data points was obtained for $8.0 \mu \mathrm{IU} / \mathrm{mL}$ of the $\mathrm{WHO}$ international standard insulin reference.

\section{Results and discussion}

The substrate-cycling reaction uses a single dehydrogenase (i.e., $3 \alpha$-HSD) as follows (23-29): $3 \alpha-H S D$ catalyzes substrate cycling between $3 \alpha$-hydroxysteroid and its corresponding 3-ketosteroid in the presence of an excess of NADH and thio-NAD because $3 \alpha-H S D$ utilizes both NADH and thio-NAD as cofactors (30). During each cycle, 1 molecule of thio-NAD is reduced to thio-NADH, which the absorbance at $400 \mathrm{~nm}\left(11900 \mathrm{M}^{-1} \mathrm{~cm}^{-1}\right)$ (i.e., $405 \mathrm{~nm}$ with a commercially available can be measured directly as an increase in
TAKE ACTION AGAINST CONTAMINATION WITH QMI $^{\oplus}$ SAFE-SEPTUM

Sample, Inoculate Or Add Nutrients To Your Bioreactor Aseptically!

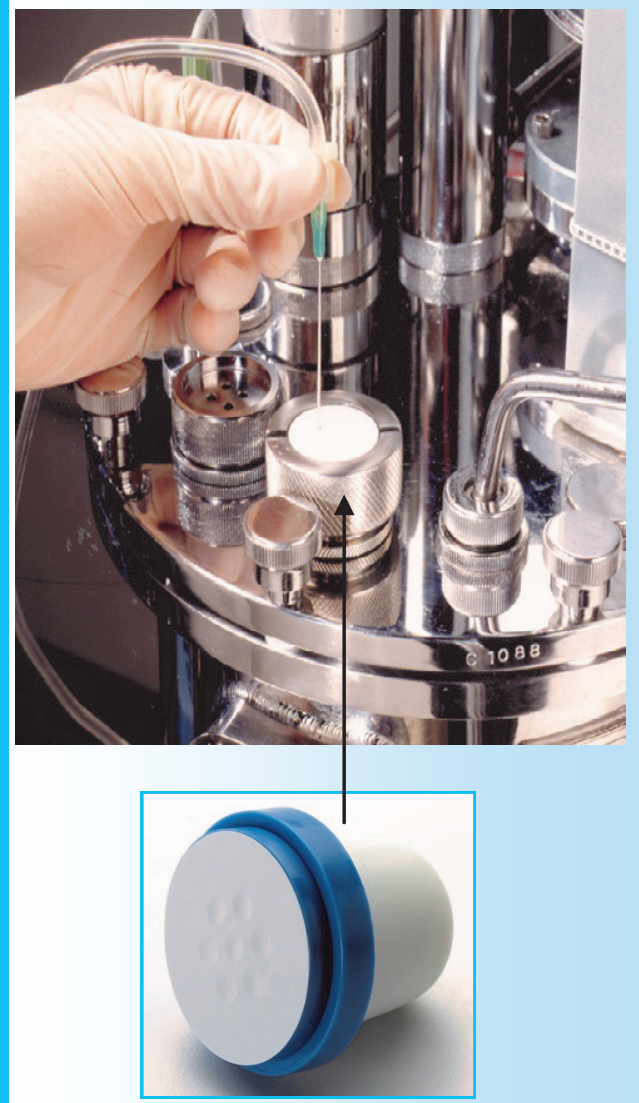

The QMI Safe-Septum is:

- Aseptic

- Pressure \& Temperature Safe

- Pre-Sterilized

- Easy To Retrofit

- Validated

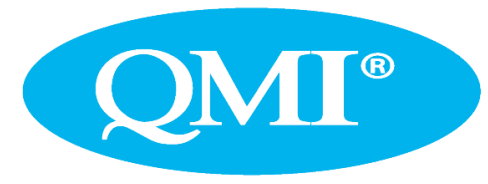

651-501-2337

Email: info@qmisystems.com

www.qmisystems.com 
microplate reader) without any interference from other cofactors such as thio-NAD, $\mathrm{NAD}$, and $\mathrm{NADH}$, the absorbance maxima of which are all $<340 \mathrm{~nm}$. These features make it possible to determine the amount of $3 \alpha$-hydroxysteroid with high sensitivity by measuring cumulative amounts of thio-NADH. This detectable signal changes linearly with time.

Our ultrasensitive ELISA coupled with thio-NAD cycling involves (Figure 1) a sandwich ELISA using a primary antibody against insulin and a secondary antibody for detection. An androsterone derivative, $17 \beta$-methoxy- $5 \beta$-androstan$3 \alpha$-ol, is produced by the hydrolysis of $17 \beta$-methoxy-5 $\beta$-androstan-3 $\alpha$-ol 3-phosphate catalyzed by AP linked to the secondary antibody. This $17 \beta$-methoxy$5 \beta$-androstan- $3 \alpha$-ol is oxidized to $17 \beta$-methoxy-5 $\beta$-androstan-3-one by $3 \alpha$-HSD with the cofactor thio-NAD. In the opposite reaction, 17 $\beta$-methoxy$5 \beta$-androstan-3-one is reduced to $17 \beta$-methoxy- $5 \beta$-androstan- $3 \alpha$-ol by $3 \alpha-H S D$ with the cofactor NADH. During this cycling reaction, thio-NADH accumulates in a quadratic function-like fashion over time.

When using the WHO international standard insulin reference, an anti-human insulin 7F8 antibody (Hytest), and an AP-linked anti-human insulin D4B8 antibody (Hytest), the ultrasensitive ELISA coupled with thio-NAD cycling in TBS yielded a linear calibration curve $(y$ $\left.=0.045 x+0.11 ; R^{2}=1.00\right)$ in the range of $0-8 \mu \mathrm{lU} / \mathrm{mL}$ (Figure $2 \mathrm{~A}$ ). This curve was obtained from the absorbance of accumulated thio-NADH at $60 \mathrm{~min}$. The LOD for the $\mathrm{WHO}$ international standard insulin reference was 19 nIU/assay, which corresponded to $\sim 1.4 \times 10^{-16}$ moles/assay. Because washing steps are included in the ELISA protocol, the absolute number of moles (on the order of subfemtomoles) that can be detected should be noted, rather than the concentration. If we convert this value to the concentration (per $\mathrm{mL}$ ), which is generally how ELISA data are expressed, $19 \mathrm{nIU} /$ assay is equivalent to $0.38 \mu \mathrm{lU} / \mathrm{mL}$, or $\sim 2.8 \times 10^{-15}$ moles $/ \mathrm{mL}$ for a $50 \mu \mathrm{L}$ assay volume. These results show that the LOD of our method is less than one-tenth of the LODs reported for conventional ELISA and lab-on-a-chip methods, as discussed above. The minimum limit of determination for the WHO international standard insulin reference was $1.0 \mu \mathrm{lU} / \mathrm{mL}$. The coefficient of variation was $9 \%$ for the $8 \mu \mathrm{lU} / \mathrm{mL}$ WHO international standard insulin reference.

Many manufacturers claim their insulin references are equivalent to the $\mathrm{WHO}$ international standard insulin reference. We compared linear calibration curves using our ultrasensitive ELISA for insulin references offered by different manufacturers. A linear calibration curve using the reference included in the $\mathrm{TOSOH}$ II insulin assay (IRI) kit was $y=0.067 x$ $0.015, R^{2}=0.99$; for recombinant human insulin from Kamiya Biomedical: $y=0.056 x$ - 0.023, $R^{2}=1.00$; for recombinant human insulin from Ray Biotech: $y=0.038 x-$ $0.025, R^{2}=0.95$; and for recombinant human insulin from BioVision: $y=0.025 x$ - $0.005, R^{2}=0.93$ in the range of $0.5-4.0$ ulU/mL (Figure 2B).

It is clear that the slopes of these linear calibration curves are different, despite claims from the manufacturers that these references are equivalent to the $\mathrm{WHO}$ international standard insulin reference. The maximum variation for these results was 35\% for $405 \mathrm{~nm}$ absorbance at 1 $\mu \mathrm{IU} / \mathrm{mL}$ insulin. For example, when we used the WHO international standard insulin reference as the antigen, the linear calibration curve was $y=0.045 x+$ $0.011, R^{2}=1.00$ (Figure 2A). These results suggest that we cannot compare the data of immunoreactive insulin among different commercially available references.

For additional recovery tests, we examined 4 kinds of sera with $280 \mu \mathrm{lU} /$ $\mathrm{mL}$ of recombinant human insulin from

Table 2. Additional recovery test for human insulin in an ultrasensitive ELISA.

\begin{tabular}{|l|l|l|}
\hline \multirow{2}{*}{ Serum } & Dilution ratio & Recovery ratio (\%) \\
\hline \multirow{3}{*}{ DM-patient serum 0 } & $1: 10$ & 90 \\
\cline { 2 - 3 } & $1: 20$ & 90 \\
\hline \multirow{2}{*}{ Control serum low } & $1: 10$ & 88 \\
\cline { 2 - 3 } & $1: 50$ & 112 \\
\cline { 2 - 3 } & $1: 100$ & 88 \\
\hline \multirow{2}{*}{ Control serum high 120} & $1: 10$ & 102 \\
\cline { 2 - 3 } & $1: 20$ & 117 \\
\hline & $1: 50$ & 124 \\
\cline { 2 - 3 } & $1: 100$ & 93 \\
\hline
\end{tabular}

Ray Biotech: (i) DM-patient serum 0 (i.e., serum obtained from a fasting DM patient), (ii) DM-patient serum 120 (i.e., serum obtained from the same DM patient 120 min after a meal), (iii) Control serum low (i.e., including $8.7 \mu \mathrm{U} / \mathrm{mL}$ insulin; QC-RE Eiken Type B Low), and (iv) Control serum high (i.e., including 78.1 $\mu \mathrm{U} / \mathrm{mL}$ insulin; QC-RE Eiken Type B High). The data are shown in Table 2. In summary, the additional recovery ratio was $100.4 \pm 13.9 \%$ (mean $\pm \mathrm{SD}, n=9$ ). These additional recovery tests clearly showed that our ultrasensitive ELISA can detect immunoreactive insulin in serum.

In the previous section, we confirmed that our ultrasensitive ELISA can be used to detect immunoreactive insulin in serum, so we next measured levels of immunoreactive insulin in DM-patient sera with our ELISA. First, blood samples were collected from DM patients for testing using the $\mathrm{TOSOH}$ II (IRI) kit to measure the serum levels of immunoreactive insulin. Next, the same samples were measured by our ultrasensitive ELISA. As shown in Figure 3A, to compare these values for DM patients, we plotted the concentration of immunoreactive insulin measured by the $\mathrm{TOSOH}$ II (IRI) kit on the $x$-axis and the concentration of immunoreactive insulin measured by our ultrasensitive ELISA on the y-axis. Here, the calibration curve used for our ultrasensitive ELISA was drawn using the same data as used for the reference insulin from the $\mathrm{TOSOH} \|$ (IRI) kit as shown in Figure $2 \mathrm{~B}$. The regression line between these two data sets was expressed as $y=1.07 x+$ 13.56, $R^{2}=0.84$ (Figure 3A). Because the slope of this line was $\sim 1$, the data from the $\mathrm{TOSOH}$ II (IRI) kit and from our ultrasensitive ELISA were in good agreement.

We also compared the data from the $\mathrm{TOSOH}$ II (IRI) kit and the data from our ultrasensitive ELISA using insulin references provided by other manufacturers (Figure 3B). When using recombinant human insulin from Kamiya Biomedical, the linear correlation curve was expressed as $y=$ $1.23 x+17.75, R^{2}=0.84$. For the $\mathrm{WHO}$ international standard insulin reference, $y=$ $1.48 x+20.86, R^{2}=0.84$; for the recombinant human insulin from Ray Biotech, $y=1.93 x+$ 26.94, $R^{2}=0.84$; and for the recombinant human insulin from BioVision, $y=2.94 x+$ 33.09, $R^{2}=0.84$ (Figure 3B). The variation in the slopes of these regression lines was very large. These results demonstrated that although our ultrasensitive ELISA can be 


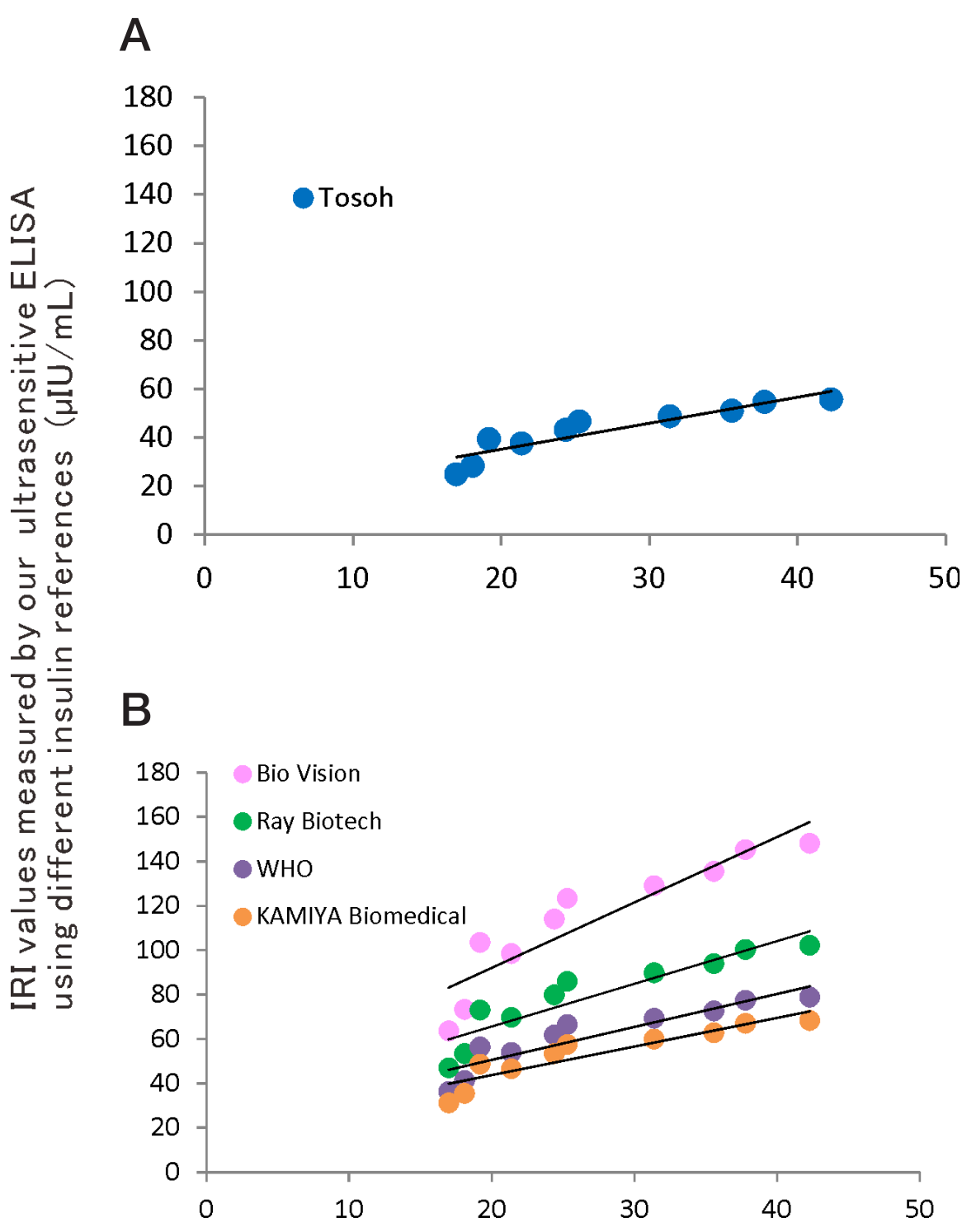

IRI values measured in

\section{Kagawa University Hospital $(\mu \mathrm{I} U / \mathrm{mL})$}

Figure 3. Comparison between the concentration of immunoreactive insulin in diabetes mellitus (DM) patients measured by a commercially available kit and that measured by the ultrasensitive ELISA coupled with thio-NAD cycling. (A) The regression line between the data from DM patients measured by Kagawa University Hospital using a TOSOH II (IRI) kit and the data measured by an ultrasensitive ELISA using the same reference is expressed as $y=1.07 x+13.56, R^{2}=0.84$. (B) Regression lines between the data measured by Kagawa University Hospital using a TOSOH II (IRI) kit and the data measured by our ultrasensitive ELISA using other insulin references that were provided by other manufacturers. For the recombinant human insulin from Kamiya Biomedical, the linear correlation curve was expressed as $y=1.23 x+17.75, R^{2}=0.84$; for the $\mathrm{WHO}$ international standard insulin reference, $\mathrm{y}$ $=1.48 \mathrm{x}+20.86, R^{2}=0.84$; for the recombinant human insulin from Ray Biotech, $\mathrm{y}=1.93 \mathrm{x}+26.94$, $R^{2}=0.84$; and for the recombinant human insulin from BioVision, $\mathrm{y}=2.94 \mathrm{x}+33.09, R^{2}=0.84$.

used for any kind of reference insulin, the values obtained using different references cannot be directly compared.

The present study showed that the LOD for the WHO international standard insulin reference was $10^{-16}$ moles/assay using our ultrasensitive ELISA. This is more sensitive than the LODs reported for other insulin
ELISA assays. This sensitivity is comparable to that for a commercially available chemiluminescent enzyme immunoassay (Lumipulse Insulin-N; Fujirebio, Tokyo, Japan), which is not colorimetric and is therefore expensive and requires a specialized instrument. By contrast, our colorimetric ultrasensitive ELISA provides several major advantages in terms of cost and simplicity, without requiring a specialized instrument. However, this sensitivity of $10^{-16}$ moles/assay does not surpass that for recombinant human insulin (10-19 moles/assay) (19) or that for HIV-1 p24 (10-18 moles/assay) (31), which have also been obtained by our ultrasensitive ELISA. This issue of sensitivity thus seems to depend on the antigen and antibodies used.

Previously it has been reported that data from different insulin immunoassays are not easily compared (32). One important issue here is the quality of the insulin reference; thus, use of recombinant human insulin has been suggested for calibration traceability (33). Indeed, when the recombinant insulin reference was used in our previous study, our ultrasensitive ELISA resulted in subattomolar detection (19). In the present study, however, we used the WHO international standard insulin reference, which was purified from human pancreatic insulin, because hospitals and diagnostic companies still use assay kits including this WHO international standard insulin reference or equivalent products. As can easily be seen, the data obtained using the different references from different assay kits were highly variable, even in our ultrasensitive ELISA. Miller et al. have suggested that all of the commercially available kits should be standardized using a pure insulin primary reference material at the manufacturer (34). We suggest that each clinical test laboratory choose one method and stick to that in order to ensure proper patient follow-up.

An ELISA for insulin generally detects intact proinsulin as well. It has been argued that an immunoassay for insulin may overestimate the true insulin levels in Type $2 \mathrm{DM}$, and subjects with impaired glucose tolerance, due to cross-reaction with intact proinsulin, C-peptide, and split proinsulin $(35,36)$. However, this is not an issue specific to our ultrasensitive ELISA, rather is an issue of the antibodies used. In any case, we examined cross-reactivity of intact proinsulin and C-peptide with the anti-insulin antibodies used in the present study. We applied $50 \mathrm{pg} / \mathrm{mL}, 100 \mathrm{pg} / \mathrm{mL}$, and $200 \mathrm{pg} / \mathrm{mL}$ of insulin, intact proinsulin, and C-peptide to our ultrasensitive ELISA and measured the absorbance of thio-NADH at $405 \mathrm{~nm}$.

In our ultrasensitive ELISA, when we increased intact proinsulin concentrations, 
the absorbance of thio-NADH increased. That is, the antibodies used in the present study do detect intact proinsulin. For example, we found that the absorbance of $50 \mathrm{pg} /$ $\mathrm{mL}$ intact proinsulin was 0.038 and that of the same volume of insulin was 0.054. Considering that the molecular masses of intact proinsulin and insulin are $9000 \mathrm{Da}$ and $5807 \mathrm{Da}$, respectively, the antibodies used cross-react with intact proinsulin at a ratio of $45 \%$. We believe that this issue originates from the antibodies used and not from our ultrasensitive ELISA method. Furthermore, the probable amount of intact proinsulin in serum is about one tenth (molar ratio) that of insulin (37-39). Because the cross-reaction ratio with intact proinsulin for the antibodies used is about $50 \%$, intact proinsulin may exert an influence upon our ultrasensitive ELISA for insulin of $\sim 5 \%$. If higher specificity to insulin is required, then more specific antibodies should be used.

For C-peptide, the antibodies used do not cross-react at all. Even when we increased the concentration of $\mathrm{C}$-peptide, the absorbance of thio-NADH in our ultrasensitive ELISA was not altered.

It should be noted that we did not try to examine the cross-reaction with split proinsulin by the antibodies used in the present study. The split proinsulin consists of only two amino acids, so any antibodies can cross-react with these amino acids. That is, the antibodies used in the present study may cross-react with split proinsulin completely or may not cross-react at all. However, the probable amount of split proinsulin in serum is about one tenth (mole ratio) that of insulin $(37,40,41)$. Therefore, split proinsulin may influence our ultrasensitive ELISA for insulin at less than $10 \%$. This is not an issue particular to our ultrasensitive ELISA method, but an issue of the antibodies used.

In the present study, our ultrasensitive ELISA for insulin needs only $5 \mu \mathrm{L}$ serum, which is equivalent to a blood sample of about $10 \mu \mathrm{L}$. Thus a finger stick or earlobe prick method for blood collection can be used in conjunction with our assay. Collecting blood from an earlobe prick instead of a vein greatly reduces patient suffering. It is also possible for DM patients to collect their own blood using a minimally invasive lancet technique for our ultrasensitive ELISA. On the other hand, a commercially available method, such as the $\mathrm{TOSOH}$ II (IRI) kit, which is used at Kagawa University Hospital, requires at least $200 \mu \mathrm{L}$ of blood, including the dead volume. Thus, the blood sample must be at least $500 \mu \mathrm{L}$.
The reduction in sample volume achieved when using our ELISA assay is an important advantage.

Furthermore, because our ultrasensitive ELISA is colorimetric, there is no requirement for special tools or chemicals such as radioisotopes or fluorescent probes. Thus, it is hoped that our ultrasensitive ELISA will pave the way for the development of a simple insulin measurement apparatus that can be easily used by general practitioners or DM patients themselves. Such an apparatus will enhance the measurement of the homeostasis model assessment ratio (HOMA-R) for resistance to insulin so that general practitioners will be able to further counsel DM patients accurately and rapidly. As such, our ultrasensitive ELISA for insulin measurement is a first step toward better treatment for DM.

In conclusion, we demonstrated that our ultrasensitive ELISA coupled with thio-NAD cycling is useful for the detection of insulin at subfemtomoles/assay in DM-patient sera, and leads to a reduction of blood sample volume required, allowing for less invasive blood sampling techniques. Recombinant human insulin, but not the WHO international standard insulin reference, should be used as a reference even in our ultrasensitive ELISA. Furthermore, as long as two suitable antibodies for a sandwich ELISA can be provided for the target protein, our ultrasensitive ELISA can be widely applied to detect trace amounts of various proteins in human sera with ultrasensitivity merely by combining thio-NAD cycling reagents with the conventional ELISA system.

\section{Author contributions}

E.I and S.W. conceived and designed the experiments. M.K., H.K., M.M., M.T., K.A., S.H., S.T., N.K., H.I., and K.M. performed the experiments. E.I., M.K., H.K., S.W., K.N., M.Y., T.Y., and T.M. analyzed the data. E.I., S.W., K.N., S.H., K.M., M.Y., T.Y., and T.M. wrote the paper.

\section{Acknowledgments}

This study was supported by a grant for the Development of Systems and Technology for Advanced Measurement and Analysis from JST, a grant for the Regional Innovation Strategy Support Program 2009 from MEXT, a grant for the New Regional Consortium Research and Development Project from METI and the Hokkaido Bureau of Economy, Trade, and Industry to E.I. and the other authors. E.I. was funded by a research grant from TAUNS Laboratories, Inc.

\section{Competing interests}

E.I, M.K., H.K., M.T., K.A., S.H., S.T., N.K., H.I., K.M., M.Y., T.Y., and T.M. declare that they have no competing interests. M.M. and K.N. are employees of TAUNS Laboratories, Inc., and S.W. is an employee of BL Co., Ltd.

\section{References}

1. Cersosimo, E., C. Solis-Herrera, M.E. Trautmann, J. Malloy, and C.L. Triplitt. 2014. Assessment of pancreatic $\beta$-cell function: review of methods and clinical applications. Curr. Diabetes Rev. 10:2-42.

2. Kahn, C.R., A.M. Jacobson, G.L. King, A.C. Moses, R.J. Smith, and G.C. Weir. 2007. Joslin's Diabetes Mellitus, 14th Ed. Lippincott Williams \& Wilkins, Philadelphia, PA

3. Dwarakanathan, A. 2006. Diabetes update. J. Insur. Med. 38:20-30.

4. Staiger, H., F. Machicao, A. Fritsche, and H.U. Häring. 2009. Pathomechanisms of type 2 diabetes genes. Endocr. Rev. 30:557-585.

5. Poretsky, L. 2010. Principles of Diabetes Mellitus, 2nd Ed. Springer, New York, NY.

6. Di Gialleonardo, V., E.F. de Vries, M. Di Girolamo, A.M. Quintero, R.A. Dierckx, and A. Signore. 2012. Imaging of $\beta$-cell mass and insulitis in insulindependent (Type 1) diabetes mellitus. Endocr. Rev. 33:892-919.

7. Wright, P.H. 1968. Measurement of insulin secretion. A review of current methods. Diabetes 17:641-645.

8. Antuna-Puente, B., E. Disse, R. Rabasa-Lhoret, M. Laville, J. Capeau, and J.P. Bastard. 2011. How can we measure insulin sensitivity/resistance? Diabetes Metab. 37:179-188.

9. Watabe, S., Y. Sakamoto, M. Morikawa, R. Okada, T. Miura, and E. Ito. 2011. Highly sensitive determination of hydrogen peroxide and glucose by fluorescence correlation spectroscopy. PLoS ONE 6:e22955.

10. Ito, E., S. Watabe, M. Morikawa, H. Kodama, R. Okada, and T. Miura. 2013. Detection of $\mathrm{H}_{2} \mathrm{O}_{2}$ by fluorescence correlation spectroscopy. Methods Enzymol. 526:135-143

11. Rzeszut, J.R. 2011. Children with diabetes: the impact of fear of needles. J. Pediatr. Nurs. 26:589592.

12. Crowther, J.R. 2009. The ELISA Guidebook, 2nd Ed. Springer, New York, NY

13. Bürgi, W., M. Briner, N. Franken, and A.C. Kessler. 1988. One-step sandwich enzyme immunoassay for insulin using monoclonal antibodies. Clin. Biochem. 21:311-314.

14. Storch, M.J., A. Alexopoulos, and L. Kerp. 1989. Evaluation of a solid-phase monoclonal antibodybased enzyme immunoassay for insulin in human serum. J. Immunol. Methods 119:53-57.

15. Mecklenburg, M., C. Lindbladh, H. Li, M. Mosbach, and B. Danielsson. 1993 Enzymatic amplification of a flow-injected thermometric enzyme-linked immunoassay for human insulin. Anal. Biochem. 212:388-393.

16. Andersen, L., B. Dinesen, P.N. Jørgensen, F. Poulsen, and M.E. Røder. 1993. Enzyme 
immunoassay for intact human insulin in serum or plasma. Clin. Chem. 39:578-582.

17. Park, J., S.L. Karsten, S. Nishida, H. Kawakatsu, and H. Fujita. 2012. Application of a new microcantilever biosensor resonating at the air-liquid interface for direct insulin detection and continuous monitoring of enzymatic reactions. Lab Chip 12:4115-4119.

18. Oyama, Y., T. Osaki, K. Kamiya, R. Kawano, T. Honjoh, H.H. Shibata, T. Ide, and S. Takeuchi. 2012. A glass fiber sheet-based electroosmotic lateral flow immunoassay for point-of-care testing. Lab Chip 12:5155-5159.

19. Watabe, S., H. Kodama, M. Kaneda, M. Morikawa, K. Nakaishi, T. Yoshimura, A. Iwai, T. Miura, and E. Ito. 2014. Ultrasensitive enzyme-linked immunosorbent assay (ELISA) of proteins by combination with the thio-NAD cycling method. Biophysics (Japan). 10:49-54.

20. Lowry, O.H., J.V. Passonneau, D.W. Schulz, and M.K. Rock. 1961. The measurement of pyridine nucleotides by enzymatic cycling. J. Biol. Chem. 236:2746-2755.

21. Kato, T., S.J. Berger, J.A. Carter, and O.H. Lowry. 1973. An enzymatic cycling method for nicotinamide-adenine dinucleotide with malic and alcohol dehydrogenases. Anal. Biochem. 53:86-97.

22. Livesey, J.H., S.C. Hodgkinson, H.R. Roud, and R.A. Donald. 1980. Effect of time, temperature and freezing on the stability of immunoreactive LH, FSH, TSH, growth hormone, prolactin and insulin in plasma. Clin. Biochem. 13:151155.

23. Mashige, F., K. Imai, and T. Osuga. 1976. A simple and sensitive assay of total serum bile acids. Clin. Chim. Acta 70:79-86.

24. Mashige, F., N. Tanaka, A. Maki, S. Kamei, and M. Yamanaka. 1981. Direct spectrophotometry of total bile acids in serum. Clin. Chem. 27:1352-1356.

25. Yoshimura, T., T. Kurosawa, S. Ikegawa, and M. Tohma. 1995. Substrate specificity of $3 \alpha$-hydroxysteroid dehydrogenase for the oxidation of fetal bile acids. Bunseki Kagaku 44:865-869

26. Ueda, S., M. Oda, S. Imamura, and M. Ohnishi. 2004. Kinetic study of the enzymatic cycling reaction conducted with $3 \alpha$-hydroxysteroid dehydrogenase in the presence of excessive thio-NAD ${ }^{+}$and NADH. Anal. Biochem. 332:84-89.

27. Zhang, G.H., A.R. Cong, G.B. Xu, C.B. Li, R.F. Yang, and T.A. Xia. 2005. An enzymatic cycling method for the determination of serum total bile acids with recombinant $3 \alpha$-hydroxysteroid dehydrogenase. Biochem. Biophys. Res. Commun. 326:87-92.

28. Matsuoka, T., S. Ueda, H. Matsumoto, and M. Kawakami. 2012. An ultrasensitive enzymatic method for measuring mevalonic acid in serum. J. Lipid Res. 53:1987-1992.

29. Iwai, A., T. Yoshimura, K. Wada, S. Watabe, Y. Sakamoto, E. Ito, and T. Miura. 2013. Spectrophotometric method for the assay of steroid $5 \alpha$-reductase activity of rat liver and prostate microsomes. Anal. Sci. 29:455-459.

30. Skålhegg, B.A. 1975. 3 $\alpha$-hydroxysteroid dehydrogenase from Pseudomonas testosteroni: kinetic properties with NAD and its thionicotinamide analogue. Eur. J. Biochem. 50:603-609.

31. Nakatsuma, A., M. Kaneda, H. Kodama, M. Morikawa, S. Watabe, K. Nakaishi, M.
Yamashita, T. Yoshimura, et al. 2015. Detection of HIV-1 p24 at attomole level by ultrasensitive ELISA with thio-NAD cycling. PLoS ONE 10:e0131319.

32. Robbins, D.C., L. Andersen, R. Bowsher, R. Chance, B. Dinesen, B. Frank, R. Gingerich, D. Goldstein, et al. 1996. Report of the American Diabetes Association's Task Force on standardization of the insulin assay. Diabetes 45:242-256.

33. Marcovina, S., R.R. Bowsher, W.G. Miller, M. Staten, G. Myers, S.P. Caudill, S.E. Campbell, and M.W. Steffes. 2007. Insulin Standardization Workgroup, Standardization of insulin immunoassays: report of the American Diabetes Association Workgroup. Clin. Chem. 53:711-716.

34. Miller, W.G., L.M. Thienpont, K. Van Uytfanghe, P.M. Clark, P. Lindstedt, G. Nilsson, and M.W. Steffes. 2009. Insulin Standardization Work Group, Toward standardization of insulin immunoassays. Clin. Chem. 55:1011-1018.

35. Temple, R.C., P.M. Clark, D.K. Nagi, A.E. Schneider, J.S. Yudkin, and C.N. Hales. 1990. Radioimmunoassay may overestimate insulin in non-insulin-dependent diabetics. Clin. Endocrinol. (Oxf.) 32:689-693.

36. Williams, D.R., C. Byrne, P.M. Clark, L. Lox, N.E. Day, G. Rayman, T. Wang, and C.N. Hales. 1991. Raised proinsulin concentration as early indicator of $\beta$-cell dysfunction. BMJ 303:95-96.

37. Sobey, W.J., S.F. Beer, C.A. Carrington, P.M. Clark, B.H. Frank, I.P. Gray, S.D. Luzio, D.R. Owens, et al. 1989. Sensitive and specific two-site immunoradiometric assays for human insulin, proinsulin, 65-66 split and 32-33 split proinsulins. Biochem. J. 260:535-541.

38. Båvenholm, P., A. Proudler, A. Silveira, D. Crook, M. Blombäck, U. de Faire, and A. Hamsten. 1995. Relationships of insulin and intact and split proinsulin to haemostatic function in young men with and without coronary artery disease. Thromb. Haemost. 73:568-575.

39. Loopstra-Masters, R.C., S.M. Haffner, C. Lorenzo, L.E. Wagenknecht, and A.J. Hanley. 2011. Proinsulin-to-C-peptide ratio versus proinsulin-to-insulin ratio in the prediction of incident diabetes: the Insulin Resistance Atherosclerosis Study (IRAS). Diabetologia 54:3047-3054

40. Clark, P.M., J.C. Levy, L. Cox, M. Burnett, R.C. Turner, and C.N. Hales. 1992. Immunoradiometric assay of insulin, intact proinsulin and 32-33 split proinsulin and radioimmunoassay of insulin in diettreated Type 2 (non-insulin-dependent) diabetic subjects. Diabetologia 35:469-474.

41. Ostrega, D., K. Polonsky, D. Nagi, J. Yudkin, L.J. Cox, P.M. Clark, and C.N. Hales. 1995. Measurement of proinsulin and intermediates. Validation of immunoassay methods by highperformance liquid chromatography. Diabetes 44:437-440.

Received 27 April 2015; accepted 17 August 2015.

Address correspondence to Etsuro Ito, Kagawa School of Pharmaceutical Sciences, Tokushima Bunri University, Shido, Sanuki, Japan. E-mail: eito@kph.bunri-u.ac.jp

To purchase reprints of this article, contact: biotechniques@fosterprinting.com
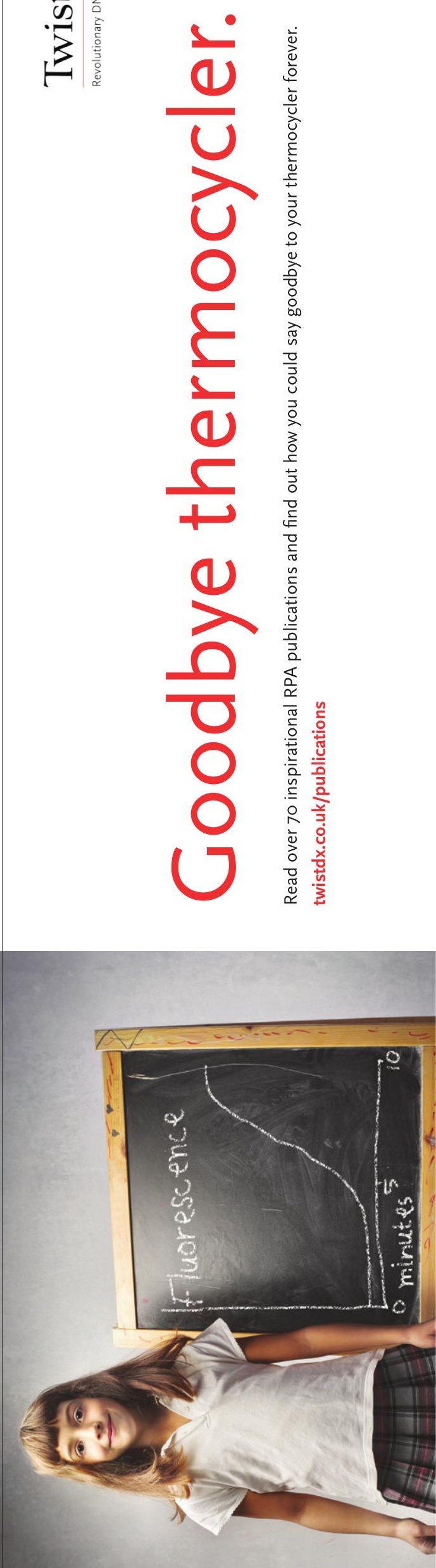